\title{
ERRATUM
}

\section{Microbial Fingerprinting Detects Unique Bacterial Communities in the Faecal Microbiota of Rats with Experimentally-Induced Colitis}

\author{
Ashis K. Samanta ${ }^{1}$, Valeria A. Torok ${ }^{2}$, Nigel J. Percy ${ }^{2}$, Suzanne M. Abimosleh ${ }^{3,4}$, \\ and Gordon S. Howarth ${ }^{4,5 *}$ \\ ${ }^{1}$ National Institute of Animal Nutrition and Physiology, Bangalore, Karnataka 560030, India \\ ${ }^{2}$ South Australian Research and Development Institute, Plant and Soil Health, Waite Campus, Urrbrae, South Australia 5064, Australia \\ ${ }^{3}$ Discipline of Physiology, School of Health Sciences, The University of Adelaide, South Australia 5001, Australia \\ ${ }^{4}$ Gastroenterology Department, Women's and Children's Hospital, North Adelaide, South Australia 5006, Australia \\ ${ }^{5}$ School of Animal and Veterinary Sciences, Roseworthy Campus, The University of Adelaide, South Australia 5371, Australia
}

In the article by Samanta et al. that appears in the Journal of Microbiology 2012; 50, 218-225. Page 218, the information of author affiliation should read as below.

\section{Ashis K. Samanta ${ }^{1}$, Valeria A. Torok ${ }^{2}$, Nigel J. Percy ${ }^{2}$, Suzanne M. Abimosleh ${ }^{3,4}$, and Gordon S. Howarth ${ }^{3,4,5 *}$}

${ }^{1}$ National Institute of Animal Nutrition and Physiology, Bangalore, Karnataka 560030, India

${ }^{2}$ South Australian Research and Development Institute, Plant and Soil Health, Waite Campus, Urrbrae, South Australia 5064, Australia

${ }^{3}$ Discipline of Physiology, School of Medical Sciences, The University of Adelaide, South Australia 5005, Australia

${ }^{4}$ Gastroenterology Department, Women's and Children's Hospital, North Adelaide, South Australia 5006, Australia

${ }^{5}$ School of Animal and Veterinary Sciences, Roseworthy Campus, The University of Adelaide, South Australia 5371, Australia 